\title{
PENGARUH DISIPLIN KERJA, LINGKUNGAN KERJA DAN KEPUASAN KERJA TERHADAP KINERJA KARYAWAN PT SAHABAT UNGGUL INTERNASIONAL KABUPATEN SEMARANG
}

\author{
Novi Octaviani ${ }^{1)}$, Dasmadi ${ }^{2)}$, Unna Ria Safitri ${ }^{3)}$ \\ Program Studi Manajemen \\ Fakultas Ekonomi \\ Universitas Boyolali \\ Email : noviocta21@ gmail.com ${ }^{1)}$, dasmadi82@ gmail.com ${ }^{2}$, unnaria68@ gmail.com $^{3)}$
}

\begin{abstract}
ABSTRAK
Tujuan dari penelitian ini adalah mengetahui adanya pengaruh antara disiplin kerja, lingkungan kerja dan kepuasan kerja terhadap kinerja karyawan pada PT Sahabat Unggul Internasional Kabupaten Semarang. Dalam penelitian ini menggunakan metode kuantitatif dengan teknik pengumpulan data melalui kuesioner.Populasi dalam penelitian ini adalah 4000 karyawan lalu diambil sampel sebanyak 364 responden. Data tersebut diolah dengan menggunakan teknik regresi linier berganda dengan bantuan SPSS 22. Kemudian menghasilkan output yang digunakan untuk melakukan analisis data pengaruh disiplin kerja, lingkungan kerja dan kepuasan kerja terhadap kinerja karyawan. Output yang dihasilkan, uji regresi linier berganda mendapatkan hasil $\mathrm{R}_{\text {Square }}$ sebesar 43,6\%. Sehingga dapat diketahui bahwa 43,6\% variabel disiplin kerja, lingkungan kerja dan kepuasan kerja mempengaruhi variabel kinerja karyawan. Sedangkan sisanya $56,4 \%$ dipengaruhi variabel lain. Hasil penelitian ini disimpulkan bahwa variabel disiplin kerja, lingkungan kerja dan kepuasan kerja berpengaruh positif dan signifikan terhadap kinerja karyawan PT Sahabat Unggul Internasional Kabupaten Semarang melalui uji simultan maupun uji parsial.
\end{abstract}

Kata kunci : Disiplin Kerja, Lingkungan Kerja, Kepuasan Kerja dan Kinerja Karyawan.

\begin{abstract}
The purpose of this study is to determine the influence of work discipline, work environment and job satisfaction on employee performance at PT Sahabat Unggul Internasional Semarang. In this study using quantitative methods with data collection techniques through questionnaires. The sample in this study were 364 respondents. The technique analysis used is multiple linear regression with SPSS 22. Then look at the resulting output how much influence the work discipline, work environment and job satisfaction on employee performance in hypothesis testing. From regression analysis tes, explained that 43,6\% variabel of work discipline, work environment and job satisfaction. Meanhile 56,4\% influenced by other variables. From the results of this study it is concludedthat work discipline, work environment and job satisfaction through partial test and simultaneous test have a positive and significant effect on employee performance at PT Sahabat Unggul Internasional Semarang.
\end{abstract}

Keywords : Work Discipline, Work Environment, Job Satisfaction and Employees Performance. 


\section{Pendahuluan}

Peningkatan produktivitas perusahaan tergantung dari sumber daya manusia sebagai asset stategis agar tujuan perusahaan tercapai secara optimal. Karena dalam Era globalisasi SDM dituntut oleh perusahaan memiliki kualitas yang baik demi terciptanya dan meningkatnya produktivitas perusahaan. Kinerja karyawan merupakan salah satu faktor yang berpengaruh terhadap produktivitas perusahaan. Di dalam kinerja karyawan, karyawan lah sebagai mesin utama sebagai sumber daya manusia. Disebut sebagai mesin utama karena karyawan yang menjalankan semua tugas dan fungsi di dalam perusahaan untuk meningkatkan kinerja karyawan. Dalam kinerja karyawan terdapat beberapa faktor yang membantunya yaitu disiplin kerja, lingkungan kerja, dan kepuasan kerja.

Dalam kenyataannya PT Sahabat Unggul Internasional faktor-faktor tersebut belum berjalan sebagaimana mestinya. Oleh sebab itu peneliti tertarik mengambil penelitian dengan tema pengaruh disiplin kerja, lingkungan kerja dan kepuasan kerja terhadap kinerja karyawan PT Sahabat Unggul Internasional Kabupaten Semarang. Dengan rumusan masalah penelitian ini adalah bagaimanakah yang telah ditetapkan yaitu ada atau tidak pengaruh disiplin kerja, lingkungan kerja dan kepuasan kerja baik secara parsial dan maupun secara simultan terhadap kinerja karyawan PT Sahabat Unggul Internasional Kabupaten Semarang. Dengan adanya penelitian ini diharapkan akan memberikan kontribusi dalam ilmu manajemen dengan yaitu mengetahui pengaruh antara disiplin kerja, lingkungan kerja dan kepuasan kerja terhadap kinerja karyawan PT Sahabat Unggul Internasional baik secara simultan maupun secara parsial.

\section{Landasan Teori Dan Pengembangan Hipotesis}

\subsection{Landasan Teori}

Menurut Veitzal Rivai (2014:13) manajemen memiliki beberapa fungsi, terdapat 2 fungsi yaitu fungsi manajerial dan fungsi operasional.

Manajemen sumber daya manusia yaitu proses untuk memperoleh, melatih, menilai dan mengompensasi karyawan dan untuk mengurus relasi tenaga kerja, kesehatan kerja dan keselamatan kerja, serta hal-hal yang berhubungan dengan keadilan. (Desller, 2015:3).

Sutrisno (2016:89) disiplin kerja yaitu perilaku seseorang yang sesuai peraturan dan prosedur kerja yang ada, atau disiplin adalah sikap, tingkah laku dan perbuatan yang sesuai peraturan baik tertulis maupun tidak tertulis dalam suatu organisasi. Fungsi disiplin menurut Hartatik (2014:186) yaitu menata kehidupan bersama antara karyawan dan pemimpin, membangun kepribadian karyawan, melatih kepribadian karyawan dan hukuman bagi karyawan yang melanggar peraturan. Bebarapa faktor yang mempengaruhi disiplin kerja menurut Sutrisno (2016:89) antara lain pengawasan pimpinan terhadap bawahan, keberanian pemimpin dalam mengambil tindakan, aturan pasti dalam perusahaan, kompensasi, dan keteladanan pimpinan dalam perusahaan.

Lingkungan Kerja menurut Soetjipto (2008:87) adalah segala suatu hal atau unsur-unsur yang dapat mempengaruhi secara langsung maupun tidak langsung terhadap perusahaan yang akan memberikan dampak baik atau buruk terhadap kinerja dan kepuassan kerja karyawan.

Kepuasan Kerja menurut Robbins (2017:170) adalah suatu sikap umum terhadap suatu pekerjaan seseorang sebagai perbedaan antara banyaknya ganjaran yang diterima pekerja dengan banyaknya ganjaran yang diyakini seharusnya diterima. 
Indikator dalam kepuasan kerja antara lain pekerjaan itu sendiri, gaji atau upah, supervise, dan rekan kerja.

Sinambela (2018:480) mendefinisikan kinerja karyawan adalah sebagai hasil evaluasi terhadap pekerjaan yang dilakukan individu dibandingkan dengan kriteria yang telah ditetapkan bersama. Tujuan kinerja karyawan menciptakan tanggung jawab setiap individu, mengelola sumber daya manusia yang dimiliki, dan membantu mencapai target perusahaan. Sinambela (2018:519) menjelaskan penilaian kinerja merupakan suatu metode atau proses penilaian pelaksanaan tugas seseorang, sekelompok orang, unit-unit kerja dalam suatu perusahan sesuai tujuan yang telah diterapkan.

\subsection{Kerangka Pemikiran}

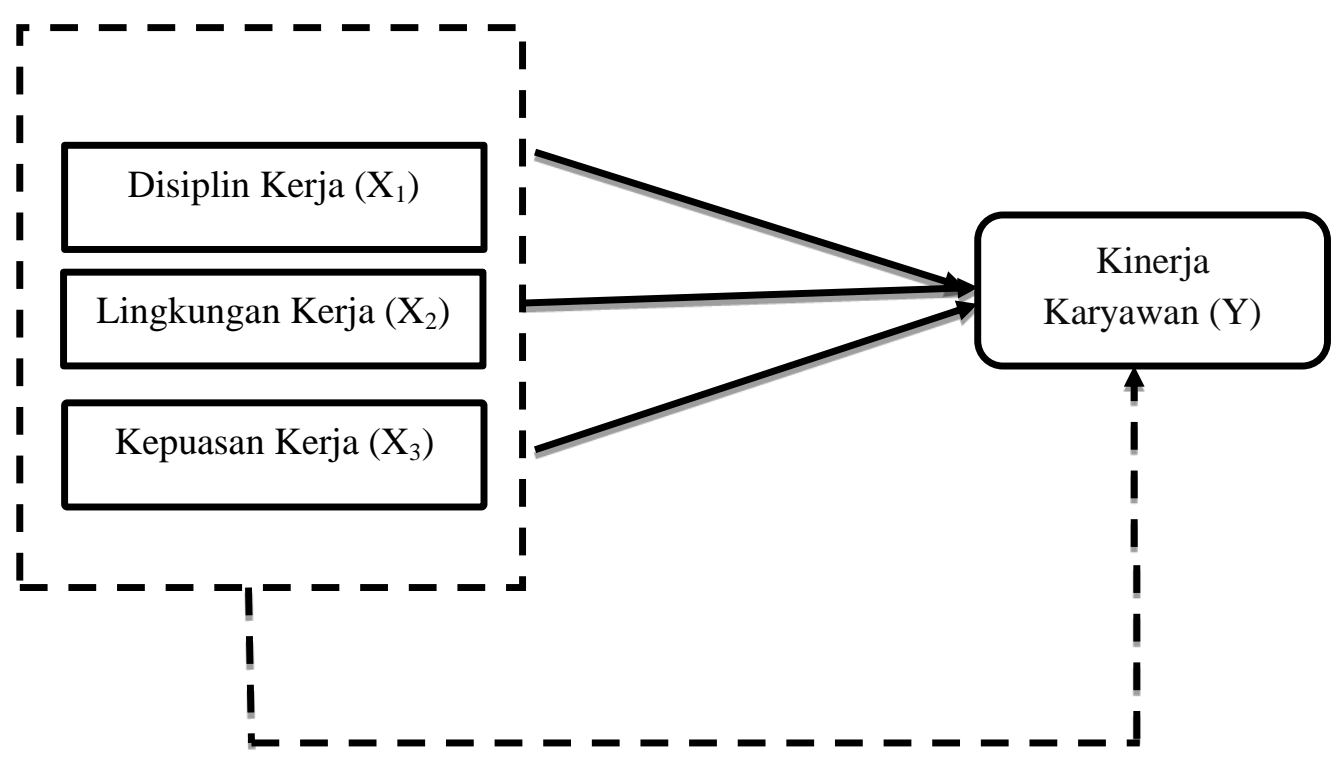

\section{Gambar 2.1 Kerangka Pemikiran}

Keterangan :

Variabel bebas (X) : disiplin kerja, lingkungan kerja, kepuasan kerja.

Variabel terikat (Y) : kinerja karyawan

Pengembangan hipotesis dalam penelitian ini adalah terdapat pengaruh yang signifikan antara disiplin kerja, lingkungan kerja dan kepuasan kerja terhadap kinerja karyawan PT.Sahabat Unggul Internasional Kabupaten Semarang baik secara parsial atau sendiri-sendiri maupun secara simultan atau bersama-sama.

\section{Metode Penelitian}

Penelitian ini menggunakan metode eksplanatori. Menurut Sugiyono (2016:8) eksplanatori adalah penelitian yang menjelaskan hubungan antara variabel-variabel yang mempengaruhi hipotesis. Obyek penelitian berada di PT.Sahabat Unggul Internasional Kabupaten Semarang yang beralamat di Jl. Raya Klepu KM 2,5 RT 7 RW 1 Klepu Kecamatan Pringapus Kabupaten Semarang. Dengan jumlah populasi sebanyak 4000 karyawan. Sugiyono (2016:80) menjelaskan bahwa populasi adalah wilayah yang terdiri atas objek atau subjek yang mempunyai kualitas dan karakteristik tertentu yang ditetapkan oleh penelitian untuk dipelajari kemudian ditarik kesimpulan. Dari 4000 populasi ditarik sampel sebanyak 364 karyawan dengan menggunakan rumus slovin dengan standar eror 5\% dan teknik pengambilan accidental sampling. Sampel adalah bagian dari jumlah dan karakteristik 
yang dimilikki oleh populasi tersebut dan sampel yang diambil dari populasi harus betul betul representatif (mewakili) hal tersebut dikemukakan oleh Sugiyono (2013:118).

Jenis data pada analisis ini ada 2 yaitu data kualitatif adalah data yang berbentuk kalimat, kata, skema dan gambar. Dan data kuantitatif adalah data yang dapat diukur atau dihitung secara langsung dalam bentuk angka atau bilangan. Data kualitatif yang diangkakan disebut juga sebagai scoring. sumber data yaitu data primer dan data sekunder. Menurut Sugiyono (2018:213) data primer ialah sumber data yang didapatkan langsung dari pengumpul data. Sedangkan data sekunder adalah data yang tidak diberikan secara langsung kepada pengumpul data biasanya dalam bentuk file dokumen atau melalui orang lain.

Metode analisis data yang digunakan dalam penelitian ini yaitu regresi linier berganda. Metode tersebut digunakan untuk mengukur antara lebih dari satu variabel bebas terhadap variabel terikat dapat diolah dengan bantuan SPSS 22. Rumus analisis regresi linier berganda sebagai berikut :

$$
\mathrm{Y}=\mathrm{a}+\mathrm{b}_{1} \mathrm{X}_{1}+\mathrm{b}_{2} \mathrm{X}_{2}+\mathrm{b}_{3} \mathrm{X}_{3}+\mathrm{e}
$$

Menurut Sugiyono (2016:172) "reliabilitas instrumen adalah kejituan atau ketepatan instrumen pengukuran. Uji reliabilitas dilakukan untuk mengetahui konsistensi dan ketepatan pengukuran, apabila pengukuran dilakukan pada objek sama berulang kali dengan instrumen yang sama.”

\section{Hasil dan Pembahasan}

\section{Tabel 4.1}

\section{Karakteristik responden menurut umur PT Sahabat Unggul Internasional Kabupaten Semarang}

\begin{tabular}{|c|c|}
\hline Usia & $\begin{array}{c}\text { Karyawan PT Sahabat Unggul } \\
\text { Internasional Kabupaten Semarang }\end{array}$ \\
\hline $20-30$ & 190 \\
\hline $31-40$ & 120 \\
\hline $41-50$ & 54 \\
\hline$>51$ & 0 \\
\hline
\end{tabular}

Berdasarkan tabel diatas dapat dijelaskan dari total 364 responden terdapat 190 responden berumur 20-30 tahun, 120 responden berumur 31-40 tahun, 54 responden berumur 41-50 tahun dan 0 responden berumur > 50 tahun. Dalam penelitian ini umur paling dominan responden berumur 20-30 tahun. Umur paling produktif dalam bekerja dalam meningkatkan kinerja karyawan.

Tabel 4.2

\section{Karakteristik Berdasarkan Jenis Kelamin}

\begin{tabular}{|c|c|c|}
\hline Jenis Kelamin & Jumlah & Presentase (\%) \\
\hline Laki-laki & 110 & $30,22 \%$ \\
\hline
\end{tabular}




\begin{tabular}{|c|c|c|}
\hline Perempuan & 254 & $69,78 \%$ \\
\hline Total & $\mathbf{3 6 4}$ & $\mathbf{1 0 0 \%}$ \\
\hline
\end{tabular}

Dari tabel diatas karyawan yang dijadikan responden sebanyak 364 responden. Responden terbanyak adalah mereka yang berjenis kelamin perempuan yaitu 254 responden. Sisinya yaitu responden laki-laki sebanyak 110 responden.

Tabel 4.3

\section{Hasil Uji Reliabilitas}

\begin{tabular}{|c|c|c|c|}
\hline Variabel & $\mathbf{r}_{\text {hitung }}$ & $\mathbf{r}_{\text {tabel }}$ & Keterangan \\
\hline Disiplin Kerja $\left(\mathrm{X}_{1}\right)$ & 0,518 & 0,098 & Reliabel \\
Lingkungan Kerja $\left(\mathrm{X}_{2}\right)$ & 0,395 & 0,098 & Reliabel \\
Kepuasan Kerja $\left(\mathrm{X}_{3}\right)$ & 0,578 & 0,098 & Reliabel \\
Kinerja Karyawan (Y) & 0,518 & 0,098 & Reliabel \\
\hline
\end{tabular}

Dengan melihat tabel diatas menunjukkan bahwa semua pernyataan adalah reliabel. Hal ini dilihat dari nilai $r_{\text {hitung }}>r_{\text {tabel. }}$ Variabel disiplin kerja memiliki $r_{\text {hitung }}$ sebesar 0,518 ,variabel lingkungan kerja memiliki $r_{\text {hitung }}$ sebesar 0,395 ,variabel kepuasan kerja memiliki $\mathrm{r}_{\text {hitung }}$ sebesaar 0,578 dan variabel kinerjaa karyawan memiliki $r_{\text {hitung }} 0,518$. Maka dari itu kuesioner yang telah dibuat dapat dipakai untuk mendukung penelitian ini. 
Tabel 4.4

Uji Autokorelasi

Model Summary

\begin{tabular}{|c|c|c|c|c|c|}
\hline Model & $\mathrm{R}$ & R Square & $\begin{array}{l}\text { Adjusted } \\
\text { R Square }\end{array}$ & $\begin{array}{l}\text { Std. Error } \\
\text { of the } \\
\text { Estimate }\end{array}$ & $\begin{array}{l}\text { Durbin- } \\
\text { Watson }\end{array}$ \\
\hline 1 &, $655^{\mathrm{a}}$ & ,429 & ,424 & ,02446 & 1,852 \\
\hline
\end{tabular}

Dari hasil analisis output SPSS 22 tabel 4.4 diatas menunjukkan besarnya nilai Durbin Watson sebesar 1,852. Dengan jumlah variabel independen tiga $(\mathrm{k}=3)$ dan jumlah sampel $364(\mathrm{n}=364)$ diperoleh nilai dl sebesar 1,818 dannilai du sebesar 1,840. Oleh karena nilai DW hitung >du, dan dengan menggunakan nilai siignifikan 5\%, makaa dapat disimpulkan tidak terjadi autokorelasi antar residual.

Pembahasan uji t:

1. Analisis terhadap variabel diisiplin kerja

Variabel disiplin kerja, apabila Sig. 0,00>0,05 maka $\mathrm{H}_{\mathrm{o}}$ diterima dan $\mathrm{H}_{\mathrm{a}}$ ditolak. Nilai Sig. 0,00 hal ini menunjukkan bahwa variabel disiplin kerja secara parsial berpengaruh terhadap kinerja karyawan, dengan kata lain variabel disiplin kerja mempunyai pengaruh signifikan terhadap kinerja karyawan.

2. Analisis terhadap variabel lingkungan kerja

Variabel lingkungan kerja, apabila Sig. 0,00 > 0,05 maka $\mathrm{H}_{\mathrm{o}}$ diterima dan $\mathrm{H}_{\mathrm{a}}$ ditolak. Nilai Sig. 0,00 analisis ini membuktikan jikavariabel lingkungan kerja berpengaruh terhadap kinerja karyawan secara parsial, dengan arti lain variabel lingkungan kerjaberpengaruh signifikan terhadap kinerja karyawan.

3. Anaalisis terhadap variabel kepuasan kerja

Untuk variabell kepuasan kerja, apabila Sig. 0,00 > 0,05 maka $\mathrm{H}_{\mathrm{o}}$ diterima dan $\mathrm{H}_{\mathrm{a}}$ ditolak. Nilai Sig. 0,04 ini artinya variaabel kepuasan kerja secara parsial berpengaruh terhadap kinerja karyawan.

Hasil uji $\mathrm{F}$ Sig. $0,000<0,05$ artinya bahwa semua variabel berpengaruh secara bersamasamaatausimultanterhadap kinerja karyawan. Dengan menggunakan tingkat $\alpha$ ( alfa ) 0,05 atau 5\% maka $\mathrm{H}_{\mathrm{o}}$ berhasil ditolak dan $\mathrm{H}_{\mathrm{a}}$ gagal ditolak. Penolakan $\mathrm{H}_{\mathrm{o}}$ dibuktikan dengan hasil perhitungan bahwa nilai Sig. $(0,000)<$ dari $\alpha$ ( alfa $)=0,05$ sehingga dapat disimpulkan bahwa semua variabel secara simultan mempengaruhi kinerja karyawan PT Sahabat Unggul Internasional di Kabupaten Semarang. 


\section{Uji Koefisien Determinasi $\left(\mathrm{R}^{2}\right)$}

Koefisien Determinasi digunakan untukmenguji goodness of fit dari model regresi yaitu seberapa besar pengaruh variabel independen terhadap variabel dependen

Tabel 4.5

\section{Hasil Uji Koefisien Determinasi $\left(\mathbf{R}^{2}\right)$}

Model Summary ${ }^{\mathrm{b}}$

\begin{tabular}{|l|r|r|r|r|}
\hline Model & $\mathrm{R}$ & R Square & $\begin{array}{c}\text { Adjusted R } \\
\text { Square }\end{array}$ & $\begin{array}{c}\text { Std. Error of the } \\
\text { Estimate }\end{array}$ \\
\hline 1 &, $660^{\mathrm{a}}$ &, 436 &, 431 & 1,475 \\
\hline
\end{tabular}

Dari tabel diatas dapat dilihat besar nilai $\mathrm{R}_{\text {Square }}$ sebesar 0,436 , hal ini menunjukkan "bahwa variabel Disiplinn Kerja, Lingkunggan Kerja dan Kepuasan Kerja secara bersama-sama mampu menjelaskan variabel Kinerja karyawan sebesar 43,6\% selebihnya 56,4\% dijelaskan oleh variabel lain selain variabel yang diteliti."

\section{Kesimpulan}

Dari hasil analisis data yang telah dilakukan, peneliti dapat menarik kesimpulan sebagai berikut :

1. Berdasarkan hasil analisis regresi berganda dengan uji $F$ secara simultan bahwa $F_{\text {hitung }}$ sebesar $92,718>\mathrm{F}_{\text {tabel }}$ sebesar 2,62 dan nilai signifikasi 0,000 $<0,05$. Hal ini menunjukan bahwa Disiplin Kerja, Lingkungan Kerja dan Kepuasan Kerja berpengaruh signifikan terhadap Kinerja Karyawan. Untuk itu dalam upaya meningkatkan Kinerja Karyawan perusahaan harus meningkatkan Disiplin Kerja, Lingkungan Kerja, dan Kepuasan Kerja. Sedangkan nilai koefisien determinasi $\left(\mathrm{R}^{2}\right)$ sebesar 0,436 memiliki pengertian bahwa Disiplin Kerja, Lingkungan Kerja dan Kepuasan Kerja secara simultan atau bersama-sama mampu mempengaruhi variabel Kinerja Karyawan sebesar 43,6\% selebihnya 56,4\% dipengaruhi oleh variabel lain yang tidak dimasukkan dalam penelitian ini.

2. Berdasarkan hasil analisis regresi berganda dengan uji t menunjukkan nilai sig. $0,000<0,05$ berarti disiplin kerja berpengaruh signifikan terhadap kinerja karyawan.Sama seperti penelitian terdahulu yang dilakukan Ery Teguh Prasetyo,Puspa Marlina (2019) yang hasil penelitiannya menjelaskan bahwa disiplin kerja berpengaruh signifikan terhadap kinerja karyawan. Hasil ini menjelaskan bahwa karyawan mempertimbangkan disiplin kerja sebagai tolak ukur pada pekerjaannya. Tanpa disiplin kerja yang baik, sulit bagi perusahaan mencapai hasil yang optimal.

3. Berdasarkan hasil analisis regresi berganda dengan uji t menunjukan nilai sig. $0,000<0,05$ berarti bahwa Lingkungan Kerja berpengaruh signifikan terhadap Kinerja Karyawan. Untuk itu perusahaan harus mempertahankan serta meningkatkan lingkungan kerja dengan sarana dan prasarana yang nyaman dan memadai guna meningkatkan kinerja karyawan. 
4. Berdasarkan hasil analisis regresi berganda dengan uji t menunjukan nilai sig. 0,044 $<0,05$ berarti bahwa Kepuasan Kerja berpengaruh signifikan terhadap Kinerja Karyawan. Penelitian ini mendukung penelitian terdahulu yang dilakukan oleh Ery Teguh Prasetyo, Puspa Marlina (2019) hasil penelitiannya menjelaskan bahwa Kepuasan Kerja berpengaruh positif dan signifikan terhadap Kinerja Karyawan. Hasil ini menjelaskan bahwa karyawan mempertimbangkan kepuasan dalam bekerja demi memperoleh hasil yang optimal. Saran

Adapun saran yang dapat meningkatkan kualitas kinerja karyawan pada PT Sahabat Unggul Internasional Kabupaten Semarang sebagai berikut :

1. Perusahaan harus tegas dalam memberikan sanksi kepada karyawan yang melakukan kesalahan dalam bekerja agar terciptanya disiplin kerja yang baik.

2. Perusahaan perlu melukakan penataan ulang ruangan untuk meningkatkan kinerja para karyawan dalam bekerja.

3. Perusahaan harus meningkatkan kepuasan kerja karyawan dengan memberi kompensasi sesuai pekerjaan mereka agar terciptanya kenyamanan dalam bekerja dan tercapai tujuan perusahaan dengan optimal.

4. Perusahaan harus semakin meningkatkan kinerja karyawan agar tujuan yang ingin dicapai oleh perusahaan tercapai secara optimal. Dengan meningkatkan disiplin kerja, lingkungan kerja, dan kepuasan kerja di dalam perusahaan.

5. Untuk peneliti selanjutnya diharapkan untuk memperluas obyek penelitian, tidak hanya variabel disiplin kerja, lingkungan kerja dan kepuasan kerja. Sehingga menambah informasi yang lebih lengkap tentang variabel apa saja yang mempengaruhi kinerja karyawan.

\section{DAFTAR PUSTAKA}

Budi W. Soetjipto,2008, "Budaya Organisasi dan Perubahan". Penerbit PT. Elex Media Komputindo. Jakarta.

Dessler,G (2015). "Manajemen Sumber Daya Manusia”. Jakarta : Salemba Empat.

Edy, Sutrisno,(2016), "Manajemen Sumber Daya Manusia”, Kencana Prenada Media Group, Jakarta.

Hartatik, Indah Puji. 2014. "Buku Pintar Membuat Operasional Prosedur", Flash Book : Jogjakarta.

Prasetyo, E.T, \& Marlina,P (2019) "pengaruh disiplin kerja dan kepuasan kerja terhadap kinerja karyawan." Jakarta.

Robbins S,P.Stephen \& Judge, Timothy A. 2017, Organizational Behaviour, Edisi 13.Jilid I, Salemba Empat, Jakarta.

Sugiyono, 2016 “Metode Penelitian Kuantitatif, kualitatif dan $R \& D$ ”, Bandung, Alfabeta.

Veithzal Rivai, 2014. "Manajemen Sumber Daya Manusia untuk perusahaan”, Edisi ke 6, PT. Raja Grafindo Persada, Depok.16956. 